\title{
The role of environmental sustainability in marketing of small architectural design practices
}

\section{Abstract}

Environmental sustainability in construction is a pressing concern. Despite their importance to the industry, and evident differences from large organisations in business strategy, markets and challenges, the literature has little to say about how small architectural design firms view the marketing potential of improved environmental sustainability. The current study aimed to address this gap, by examining practitioner experience of sustainability and marketing in small architectural design practices. Semi-structured interviews were conducted with 16 such practices. A critical interpretive stance was adopted in analysis, drawing on the theoretical framings of Service Dominant Logic (SDL) and relationship marketing. Sustainable design is part of the co-creation of value in architecture, enhancing the value proposition beyond a cost basis. Its inclusion contributed to business development through referrals. Taken together, co-creation of value and asymmetry of knowledge between professional and client drive the conclusion that the architectural designer has primary responsibility in guiding clients towards greater environmental sustainability. This responsibility and the role of sustainability in business development were not necessarily recognised by the designers. Insights from SDL challenge assumptions that cost and lack of client demand prevent greater sustainability in design.

Keywords: architect, environmental sustainability, relationship marketing, servicedominant logic, small business. 
Environmental sustainability in construction is a pressing concern for the industry globally (Kibert, Sendzimir and Guy 2000). The construction industry uses around $40-50 \%$ of all raw materials extracted globally and, as a sector, is the largest contributor to carbon emissions (United Nations Environment Programme 2014). Between a quarter and one third of all waste generated in Europe comes from construction and demolition (EU 2015) and a third of energy use is by buildings (Knight, Chan and Singh 2014). In the UK, the Climate Change Act 2008 set a national target for reduction by $80 \%$ of carbon emissions by 2050 against a 1990 baseline. To meet the legal requirements of the Climate Change Act, the UK Green Building Council estimates that a drop of $68 \%$ in embedded carbon in extraction, processing and manufacture of building materials and a reduction of $84 \%$ in operational energy of buildings are necessary. Substantial change is clearly required of the industry and marketing has a role to play. Given the many meanings of the term 'sustainability', the paper begins with a brief outline of the problems with, and approaches to, definition, including environmental assessment standards for buildings, and 'green marketing'. The discussion then moves on to consider theoretical approaches to marketing, specifically relationship marketing and servicedominant logic; and marketing in professional services firms, in architectural practices in particular and in small-to-medium enterprises (SMEs) in general. The argument is made that the differences between small and larger organisations are frequently overlooked and that there is a dearth of empirical work on small and micro businesses despite their predominance in the UK construction sector. This points to the gaps in the literature which the current study aims to address, and explains the focus of the study on the role of environmental sustainability in the marketing of small ${ }^{\mathrm{i}}$ architectural design practices. 


\section{Definitions of sustainability}

In order to examine sustainability in marketing, an agreed definition of 'sustainability' would be expected ${ }^{\mathrm{ii}}$. Brundtland's much-quoted definition of sustainable development (World Commission on Environment and Development 1987) has been critiqued as somewhat vague, with potentially mutually conflicting objectives, and meanings of sustainability have since proliferated (Hopwood, Mellor and O'Brien 2005, Johnston et al. 2007). Amongst a number of attempts within the academic literature to impose definitional order, Hopwood, Mellor and O’Brien (2005) usefully mapped definitions of sustainable development onto the dimensions of environmental and socio-economic concerns. They demonstrated that fundamental incompatibilities between definitions within different approaches to sustainable development could be understood with respect to their location on this framework. Thus, for example, ecological modernisers could be seen as showing moderate concern for environmental issues and supporting minor changes to the status quo, whereas an eco-feminist perspective would rate environment concerns more highly and tend to seek radical transformation of existing systems and politics. In seeking definition of sustainability in construction, the same tensions are evident, with definitions typically grounded in a particular perspective (Halliday 2007 - tending towards a radical/transformative view) or emerging from a mix of perspectives (Hill and Bowen 1997 - tending towards the status quo/incremental change), though typically without reflecting on the particular perspective influencing the definition. In contrast, in his brief overview of the status of sustainable construction, in understanding and in practice, Kibert (2007) notes that progress on green buildings has been incremental rather than radical. He goes on to point to the salience of varied roles in construction, from financiers to architects. This raises the important issue of 
ensuring the relevance of definition with respect to different professional roles. Roles in construction are not homogenous (Cole 2011). Principles of sustainability within the scope of influence of a property developer may differ substantially from those within the scope of a services engineer, for example.

Without explicitly defining what is meant by sustainability in construction, the UK Government's interpretation has included, as primary aspects, not only water, waste, materials and biodiversity, but also the vaguer aims of climate change mitigation and adaptation (HMG 2008). As part of attempts to address the problematic definition of sustainable construction, standards for environmental assessment of buildings have been introduced in many countries since the 1990s (Lee 2013). Of these standards, the UK's BREEAM (Building Research Establishment Environmental Assessment Method) and the US LEED (Leadership in Environmental and Energy Design) are seen as the most comprehensive (ibid.). Initially voluntary but now mandatory in specific contexts (e.g. specific standards of BREEAM compliance are required for all government procurement in the UK), BREEAM assessment allocates credits across nine domains including energy, materials and waste, and then calculates an overall rating ranging from 'poor' to 'outstanding' from the weighted combination of scores. In an insightful exploration of the meanings of BREEAM as a socio-technical system, Schweber (2013) argued that, while certification schemes such as BREEAM are seen as a useful independent indicator of sustainability for clients with limited in-depth expertise of sustainability, to knowledgeable professionals, they are equally seen as proxies for sustainable construction which carry implicit limitations and constraints to 'genuine sustainability'. The policy intention behind BREEAM and similar assessment tools was, in part, to drive increased market value of sustainable buildings (ibid.). Thus, 
although standards such as BREEAM may be used to indicate how 'sustainable' a building is, such tools emerge from and serve particular political and economic worldviews and are in themselves contested. Nevertheless, such standards serve usefully to ground discussion. For the current study, we were sensitive to three topics of relevance for design professionals in the construction industry (energy efficiency, materials, health and well-being), selected from the nine domains which BREEAM measures. It is important to note that, while this represented our understanding as we approached our study, our participants - and their clients - had potentially differing understandings and we discuss this in the analysis below.

\section{'Green' Marketing}

Research across sectors on 'green marketing' has demonstrated financial and competitive advantages (Ambec and Lanoie 2008, Leonidou, Katsikeas and Morgan 2013). Beyond competitive advantage, there are image benefits to stakeholders (Sarkis, Gonzalez-Torre and Adenso-Diaz 2010) and, increasingly, environmental sustainability is seen as essential in strategic marketing for commercial legitimacy (Chan, He and Wang 2012). Sustainable buildings may provide higher value through cheaper operation, less likelihood of obsolescence, higher quality of life for occupants and improved image for the owner (Schneiderová Heralová 2011).

In diverse sectors, large organisations are aware of the importance of environmental reputation. For example, BT Group and other leading commercial organisations have committed to $100 \%$ renewable power for their operations (The Climate Group 2015). Environmental concerns are frequently addressed as part of a broader corporate social responsibility agenda which is held to contribute to reputation and brand (Miller and Merrilees 2013, Czinkota, Kaufmann and Basile 
2014), and image and reputation (Dodds, Graci, Ko and Walker 2013), although this may be sector dependent (Leonidou, Katsikeas and Morgan 2013).

Despite the apparent consensus on its benefits, the meaning of 'green marketing' is far from agreed. The American Marketing Association defines green marketing with reference to pollution and energy conservation ( $\mathrm{Li}$ and Cai 2008), a narrow focus which ignores sustainable sourcing of raw materials and impact on biodiversity, for example. Li and Cai (ibid.) and others take a broad and high level view, defining green marketing as relating to all activities which have environmental impact. An alternative perspective is that of Liu et al. (2012) who define green marketing activities with respect to target markets of social- and environmentallyconscious consumers. Attempting to bring together diverse positions on green marketing, Menon and Menon (1997) defined three levels of 'greening' in organisations: tactical, in which functional activities are changed; quasi-strategic, in which major changes in processes are instigated; and strategic, in which corporate culture changes. In construction, Smyth (2013) also proposed three levels of greening in major organisations, though with an external focus in contrast to Menon and Menon's intra-organisational perspective: regulatory compliance, alignment with best practice within the sector, and technical or service innovation. Although these framework approaches do not address issues around the scope of activities to be considered, they draw attention to levels of engagement with the sustainability agenda. There has been strong argument in the literature on the risks of 'tactical greening', with warnings of customer scepticism at 'green hype' (Chen and Chang 2013, Lyon and Montgomery 2013). Indeed, there is some evidence in construction research that major organisations may as yet be 'paying lip service' and addressing environmental concerns at a superficial level (Myers 2005, Smyth 2013). 
In their examination of green marketing, some scholars appear to have considered only strategic change and argue that a holistic shift is required in organisational 'mindset' and culture (Polonsky and Rosenberg 2001). Such arguments can be positioned within the 'deep ecology'/ 'deep green' philosophical and political perspectives of radical environmentalism (Devall 1991, Hopwood, Mellor and O'brien 2005). Polonsky and Rosenberg (ibid.: 21) also warned of “opportunistic tactical greening", arguing that "its early use caused long-term damage to genuine environmentally responsible activities". However, therein lies part of the definitional problem presented by green marketing and environmental sustainability more generally: what constitutes 'genuine environmentally responsible activities'? In construction, for example, a petrochemical-based polyurethane insulation material can be more thermally efficient than a wool or straw insulation panel of equivalent dimensions (Szokolay 2014). The architect must therefore balance energy efficiency over the building's lifespan with use of non-renewable materials, amongst other factors. Taking a philosophy/ethics-based perspective, Farmer and Guy (2010) noted that sustainability fulfils the definition of a 'wicked' problem (Rittel and Webber 1973), with characteristics including lack of a definitive formulation and the adequacy of resolutions adjudicated by different stakeholder groups. They proposed a pragmatic philosophical perspective in which sustainable construction is understood as situationally contingent. While this illuminates some of the difficulties of defining sustainable construction, it presents a challenge for green marketing: if the meaning of sustainability varies between contexts, the meaning of green marketing must also vary. Thus it is evident that understandings of environmental sustainability, of green marketing and of 'greening' in organisations, and the relationships between these concepts, remain contested, with philosophical, 
political, sector-specific and pragmatic perspectives to consider. Nevertheless, as is clear from the introductory discussion, sustainability is of major importance to society, to business in general and to construction in particular. With different viewpoints under debate within the academic literature, it is particularly important to build empirical evidence of how sustainability and its marketing are being implemented by practitioners today. We turn now to theoretical understanding of marketing and then briefly review theoretical and empirical studies relevant to marketing in small architectural practices.

\section{Marketing}

Three major paradigms in marketing research over the past 50 years may be identified. An early product focus, emerging from industrialisation and mass production, took the firm-customer exchange as the focal transaction, which was understood to be unitary and short-term, and aimed at meeting customer requirements at a profit (Grönroos 1996). In contrast, the relationship perspective on marketing considers the dyadic relationship as the focal unit (ibid.) The relationship develops over time (Finne and Grönroos 2006), underpinned by communication, commitment, trust (Smyth 2015) and gratitude (Palmatier et al. 2009). Relationship marketing aims to secure new work through systematically seeking to manage and add value to relationships (ibid.) and may be particularly pertinent to small businesses, as we discuss in the next section.

In addition to a relationship marketing perspective, a more recent theoretical viewpoint is that of service-centred dominant logic (SDL) in which the unit of commercial exchange is the application of specialised skills or knowledge (Vargo and Lusch 2004, 2008). Within an SDL, the production enterprise constructs value propositions which optionally may involve the consumer but value per se is always a 
co-creation (Vargo and Lusch 2015). Value realisation resides in the client's experience, that is, in 'value-in-use' and, crucially, value is no longer considered in economic terms alone. Such co-creation of value-in-use can be seen as inherent to many professional services offerings, and appears particularly relevant to architectural design services, in which client and architect may collaborate closely in the design process. The most recent updates of the SDL framework, consolidated in Vargo and Lusch (2015), include a move from a dyadic to a multi-actor focus. Value creation is proposed to occur in networks and all actors enact processes of integrating resources and exchanging services, although not in identical ways. The conceptualisation of value and recipient has broadened to encompass reciprocal service provision and value co-creation, within an "ecosystem" of social institutions and institutional arrangements.

The theoretical approaches of relationship marketing and SDL appear to offer insights into the nature and processes of the services offered by architectural design practices and how such services may underpin their approaches to marketing. However, although relationship marketing has been explored to some extent for architectural practices, as yet in this domain, the insights of SDL have yet to be applied, and neither has been harnessed in exploring the current role of sustainability or its future potential. We now provide a brief overview of current understanding of marketing in architects' practices before specifying the research question.

\section{Marketing in architects' practices}

Previous research on marketing in architects' practices has tended to include them as professional services firms (PSF) (e.g. Reid 2008) . Professional services are considered to be intrinsically relational and service-oriented (Sweeney et al. 2011). Indeed, "most professional services firms practice some form of relationship 
marketing whether they specifically recognise it or not" (McColl-Kennedy et al. 2008: 30) although pluralistic approaches tend to be common (Reid 2008).

Definitions of professional services apply to architectural services in many respects. However, in an early attempt to develop a theory of professional services marketing, Gummesson (1978) noted the heterogeneous nature of PSF and argued that appreciating the differences between them is essential to understanding the nature of their business and their opportunities for successful marketing. A seminal longitudinal study on architectural practices, before and after a period of economic downturn in 1970s' New York, pointed to creativity as a key differentiator between architectural and other PSF (Blau 1984). Further, architectural practices were seen to grapple with a series of 'Daedalean risks' (ibid.): tensions between business success and design aspiration, between aesthetic desires and client needs. Understanding the potentially unique challenges of marketing for architectural practices is therefore important but relatively little research here has been conducted (Smyth and Kioussi 2011).

In a theoretical development offering important insight into business and marketing strategies in architectural practices, Winch and Schneider (1993) differentiated firms along two dimensions: complexity of project and client versus peer review of quality, to suggest four forms of strategy. In brief, strong delivery businesses deliver relatively simple projects to answer the client's brief, with a focus on cheap and efficient delivery. Strong experience businesses undertake more complex projects and quality is determined by the outcome rather than in concept. In contrast, strong ideas and strong ambition practices aim to deliver conceptually innovative signature buildings, acclaimed by peers, working in the 'star' system or winning competitions. With different organisational strengths and target markets in 
each quadrant, Winch and Schneider's model clarifies that different approaches to marketing will be appropriate for different types of architectural practice. However, in contrast to such a theoretically-informed prescriptive approach, empirical studies have discussed a general 'professional distaste' by architects for advertising and marketing (Blau 1984, Mccoll-Kennedy et al. 2008, Smyth and Kioussi 2011) and found evidence of little or no resources dedicated to marketing activities (Sullivan 2000). An (albeit small-scale) empirical study which built on Winch and Schneider's (1993) model suggested that both brand management and key account management may be suitable approaches for practices falling within the strong ideas and strong ambition quadrants, but noted that, in practice, relationship marketing may be conducted implicitly without proactive management (Smyth and Kioussi 2011).

What is missing from previous studies on marketing in architectural practices is a focus on small practices: small firms have either been included with (and dwarfed by) larger businesses (Blau 1984), not explicitly considered (Winch and Schneider 1993) or firm size was not presented (Smyth and Kioussi 2011). Yet small businesses may have less resource to commit to formal marketing activities such as market research and lead generation, and existing measures of marketing activities may not be suitable for small firms in which many indicators or activities may be integrated in one person (Raju, Lonial and Crum 2011). Many small architectural practices in particular may fall into the strong delivery category as defined by Winch and Schneider (1993). It is worth noting too that growth, market share and financial success are not necessarily the goals of all small firms: small businesses may aim to maintain the status quo to support the lifestyle of the owner-manager (Ates and Bititci 2011). Within the literature on SMEs more generally, traditional, transactional approaches tended to position SMEs as lacking understanding of marketing. 
However a relationship marketing perspective sees SMEs as primarily focused on relationships (Coviello, Brodie and Munro 2000), with customer relations seen as critical (Payne and Frow 2005). In one of the few studies to pay attention to business size in architectural design firms, smaller firms were found to be more likely to be 'marketing non-users', with a strong focus on immediate client requirements, service and design quality, in contrast to medium-sized and large businesses that additionally had longer-term goals including innovation, growth and recognition (Barksdale and Clopton 1994). Within construction, the potential applicability and benefits of relationship marketing and management have been considered for large contractors (Mayer, Davis and Schoorman 1995, Smyth and Fitch 2009) but not for small firms. Previous work then suggests that for small architectural practices, relationships may be key although little formal attention may be paid to marketing. The role of sustainability is unknown. Given the distribution of firm size in architecture, a focus on large organisations leaves important facets of the industry unexamined. A recent survey of chartered practices of the Royal Institute of British Architects noted that "the profession is shown to comprise a myriad of extremely small businesses" (Royal Institute of British Architects 2014). Although most firms have a variety of client types, the pattern varies by size: for practices with one or two architects, more than $60 \%$ of work is on private housing; for firms of over 30 , this drops to under $5 \%$ (The Fees Bureau 2013). Thus architecture in the UK is highly differentiated, with small practices in many ways very different types of business from large, with different markets, margins and challenges. This difference however is not echoed in the research literature, with few studies including small architectural practices and no studies to our knowledge having explored the role of environmental sustainability in solely small architectural practices. 
The overview of the academic literature then has suggested that there is a need for greater focus on small architectural practices, for application of the new theoretical insights of SDL and, despite the difficulties of definition, to examine the role of environmental sustainability. The current study aims to make a novel contribution by addressing these gaps, focusing specifically on practitioner experience in small firms offering architectural design services. In the current work, we are not attempting to extend theory but to apply existing theories where appropriate, specifically SDL and relationship marketing, to aid understanding of the current and potential future role of sustainability in marketing small architects' practices. This study is the first attempt, to our knowledge, empirically to investigate marketing and sustainability in the very small practices which comprise a sizeable proportion of the UK industry.

\section{Methodology and Method}

Our epistemological position for the research is that of critical realist (Harré 2009), to extend previous research on SMEs and sustainability which has tended to take a realist position. Whereas earlier studies provided useful insights in showing that SME architects perceived barriers of cost and lack of demand hindering the inclusion of sustainability in their work (Revell and Blackburn 2007), we take a critical interpretative stance to move beyond their preliminary discourses. We chose a method congruent with our epistemology, that of semi-structured qualitative interviews with thematic analysis (Braun and Clarke 2006). An established analytic method, thematic analysis permits the critical analysis of latent themes. Thus the researcher can go beyond surface readings of accounts and seek patterns, explore contradictions and forge linkages to external factors, including theory if appropriate, 
to build deeper understanding of the phenomenon in question. The method does not claim statistical generalisability as quantitative methods do, but the case may be made for theoretical generalisability and it has been argued that rich, qualitative analysis offers more realistic findings that those from quantitatively aggregated analyses of factors pre-determined by the researcher (Smyth and Morris 2007).

In the current study, the owner-managers of 16 businesses were interviewed. All were micro-enterprises (fewer than 10 employees), with 11 practices of one or two employees, and five practices ranging from 5 to 9 employers. Of the participant firms, 13 offered architectural design services, two were structural engineers and one was a landscape designer business. No salient differences were noted between the responses of the latter three firms and the architects' practices. The participants were involved on projects ranging from several hundred pounds up to $£ 3$ million. Most projects serviced the residential sector, mainly extensions and refurbishments as well as new build, although larger projects, including multiple unit residences, schools and commercial developments were also in evidence. All firms could be categorised as strong delivery in Winch and Schneider's (1993) typology.

The interviews were conducted as part of a project offering basic training in eco-design to SMEs in construction. As such, the participant businesses will have considered themselves non-expert in sustainability (e.g. none had ISO14001 or equivalent accreditation) but had sufficient interest to take part. Organisations were recruited through a combination of personal and professional networks, and approaches to companies listed in an online construction directory. The selection criterion was simply SME in architectural design although from the online database (which yielded three participants), recruitment targeted smaller practices by approaching firms of 10 or fewer employees. A small number of participant firms 
were medium-sized and were excluded from the analysis. Interviews were conducted with the business owner-managers, and in most cases also included employees. The interview plus training sessions lasted between one and two hours and were audiorecorded and transcribed verbatim. Qualitative analysis software, NVivo V10, was used to aid analysis. In the analysis below, extensive use is made of quotations from the participants to demonstrate that the findings are grounded in the data. The participant number is given for each extract (e.g. [P1] = Participant 1).

The session opened with general questions on the type and size of building projects in which the firm usually engaged and what sustainability meant to their business. Follow-up questions were posed on the extent to which clients requested sustainable solutions and what sustainability means to clients. After the training component, general discussion followed around the challenges of including sustainability in architectural design.

Following recommended methodological guidelines (Braun and Clarke, 2006), analysis proceeded by detailed reading of all transcripts, followed by coding of segments of text guided by the research question. Coding progressed with constant referral back to the transcripts until all interviews were coded and each code linked to each transcript as appropriate. Coded segments were then aggregated into themes based on conceptual similarity and the most prevalent themes selected for the narrative account below.

\section{Analysis}

\section{Limited client demand}

The participant designers were clear that their service was "client-led" [P4]. "It's the client that makes the choice" [P16] even if the brief is contradictory. The client was 
positioned as wielding greater power than the designer:

But ultimately the client specifically asks for something, you kind of have to give them... you can't be completely the opposite to that. You can offer the other one, but if they want stone, you're suggesting actually stone might not be the right material, but they're absolutely adamant they want stone, they have to have stone, haven't they? [P10]

Within this context, the designers we spoke to saw very limited demand for sustainable construction:

Just occasionally you'll get the odd client who will put it high up on the agenda...But you know the number of people who come along with a sort of a conscious agenda are fairly small, I'd say. [P2]

Their perception mirrors research evidence for limited interest by householders in sustainable technologies (Christie, Donn and Walton 2011) and more generally, for limited interest by clients of SMEs in sustainable construction (Revell \& Blackburn 2007).

As BREEAM was developed in part to drive market demand in sustainability, it would be expected to feature in the participants' responses. However, half of the designers made no mention. Several described it as 'box ticking', implying a bureaucratic exercise which, for them, had limited impact on sustainable construction. One participant saw positive benefit in its objective appraisal of a project. In contrast, another described it as a "nightmare" on a small project. Only one participant mentioned BREEAM as a marketable aspect of a building (rather than for his practice) but seemed unsure about how clients may view it. For the architectural designers in this study then, BREEAM-accredited design was not perceived as a marketing benefit. Equally, other sustainability frameworks, such as 
RIBA's Green Overlay to the Plan of Work or ISO14000 Environmental

Management Standards were not mentioned by any participant, suggesting that formal systems approaches to sustainability had not become embedded in the working experiences of the small architectural practices we interviewed.

In some cases, the participants identified the (missed) marketing potential of a sustainable approach for construction professions other than themselves, including manufacturers of construction products and builders. However, for themselves, few considered that sustainable design provided an enhanced marketing offering. Participant 16 said: “We don't use it as a unique selling point. We don't say that we're the most sustainable practice", even though sustainability was "omnipresent" in their designs. On initial assessment then, this would suggest that small architectural design businesses do not consider environmental sustainability as contributing to or strengthening their marketing content or processes. An inspection of the websites of the participant firms after the interviews found that of the 12 businesses with a website, 9 had no or very minor reference to sustainability. The participants appeared to link the lack of its importance to their perception of limited client demand. This has been noted in previous research (Revell and Blackburn 2007) but is included here as grounding for further analysis, beyond that conducted in earlier studies. As Harré (2009) noted, reasons are not causes and further critical analysis of the participants' responses shows a rather more complex picture. A number of factors emerged associated with why the participants appeared to discount the potential of sustainable design for marketing. Nonetheless, sustainable design was intrinsically bound into the services they offered, to the extent that it could be seen to enhance the potential for future business. We will now discuss evidence from the interviews on why the marketing potential of sustainability may be overlooked within small design firms in 
construction, before moving on to show how sustainable design was in fact part of the value proposition to clients and, in this way, intrinsic to development of future business.

\section{Different understandings of sustainable design}

One reason why the prevailing perception by the architectural designers was of very limited client demand, and therefore poor marketing potential, for sustainability may be due to the discrepancies between designer and client understanding of what sustainability encompasses. The interviews showed marked differences in how designers and client defined what constituted 'sustainability'.

For the designers, their definitions of sustainability were typically broad and encompassed a wide-ranging and conceptual understanding. For example, the definition by P15 included "to make as little change as possible...build less, essentially", seeing sustainability as being "about the quality of the design". Others defined sustainable architectural design with reference to "designing fabric first", careful design to minimise reliance on technologies, use of passive solar gain, stack ventilation, thermal mass, layout, orientation, and considering suitability for use. A secondary factor for designers was material choices. In contrast, almost all client requirements were for products, particularly photovoltaic (PV) panels and solar thermal water heating but also sedum roofs, air source and ground source heat pumps. The clients' understanding can be seen to be limited to the visible technologies associated with environmental sustainability whereas the designers understood the extent to which the design itself incorporated sustainability principles and could lead to lower energy consumption and greater comfort and usability. The designers noted the lack of understanding on the part of their clients. Participant 2 
specialised in refurbishment and minor works to older homes and, in a recent case, had recommended internal insulation in a cold bathroom:

I don't think she'd really considered that there was anything she could do, somehow. But you know she'd just thought it was an old house, this is what you get if you're living in a Victorian terraced house...A lot of people feel that if they don't have a cavity to be filled they can't do anything [P2].

Even where clients were interested in a sustainable approach, their understanding tended to be shallow: "The whole eco design thing... it's just a buzz word... and most people don't understand the full scope of it" [P1]. P10 expressed this particularly clearly:

I find clients generally have quite a simplistic view of sustainability.

I think some of the views are well intended and genuine, however I think they do manifest themselves in almost particular product choices. I haven't met a private client that's got a kind of overall view that's kind of set me targets in the general sense, almost performance targets. [P10]

This speaks to the issue of widely varying meanings of sustainability, as discussed above.

Of the designers interviewed, most demonstrated knowledge of many aspects of sustainability (although almost all noted that they would like to know more). In two cases however, knowledge of sustainable construction appeared limited and these two businesses were more negative about the potential benefits of sustainability. This indicates that there are small design practices who do not seek to 
use sustainability as part of marketing practice through lack of personal interest or knowledge.

\section{Cost as primary concern}

A further reason why the architectural designers appeared to feel that sustainable design did not offer marketing potential was the focus on cost in many projects, and the assumption that anything perceived as 'extra' would not be accepted in a design proposal. This linked to the clients' perceptions of sustainability as relating to products or "bolt-ons" which would often be removed in deliberations around project cost. P5 described a school project with more opportunities [for sustainable design] ... but ... the value engineering is very lowest common denominator and then subsequently was hammered under VE [value engineering] and most of the good bits were taken out. [P5]

In general, the designers were very conscious of cost on behalf of their client: "small projects like an extension we'll definitely try to consider a smaller fee and do it as cheap as possible." [P4]. However, they differentiated between different types of clients and different priorities. P14 suggested a categorisation of clients:

If I want to categorise our clients, we have clients that they just want a job to get done, in the cheapest possible way...So for this sort of client, we really don't open up this sort of discussion... but sometimes, we have had clients, that they started saying that, okay, I'm looking for something that is eco-friendly, but they didn't use the word sustainable... We had this sort of clients, but rarely. [P14]

Several participants had worked with developers, whom they described as much more cost-focused than homeowners: 
It's easier to argue the case [for sustainability] when you have a private client, and it's their own home, but when we worked with a developer. They're extremely short-sighted. It's what they have to pay for now...they understand the price of everything, and the value of nothing. [P15]

The two practices that appeared to have more limited knowledge of sustainability linked sustainable design to cost from the outset, in contrast to the other practices that were aware of how aspects of sustainability could be incorporated for no cost: "designing in a responsible way doesn't necessarily cost the client money" [P9]. For some design practices then, possibly due to lack of knowledge, their association of sustainability with extra cost may contribute to their discounting of its possible marketing benefit. Again, cost has been noted previously as a factor which discourages small businesses from engagement in sustainability (Revell and Blackburn 2007) but is posited here as a premise from which to argue that benefits beyond cost are actively negotiated between architect and client. A key tenet of an SDL perspective is that value is no longer considered in economic terms alone and this insight illuminates how architects approached their service offering.

\section{Benefits beyond cost}

Despite the strong focus on costs, most of the designers were aware of other priorities for their clients, for example: "I think on these smaller scale projects where ... it's probably just as much about money but it's also about comfort and creating a home" [P9]. They made explicit reference to client objectives that may not have been in the brief, acknowledging for example that a private client may be "putting all their life savings into their dream house" [P10]; the long-term impact of the design on the household for private clients; and making a leased commercial building appealing to 
a particular type of tenant to maximise the developers' return. The architectural designers drew on their knowledge, experience and insights into what clients really wanted or needed to provide excellence in design and value-in-use to the client. The participants spoke of their motivation to delight the client, to provide "good", "quality" and "responsible" design. They provided a number of examples of seeking to enhance the value-in-use to the client that the design provided, for example:

It's even things like recognising the area that you're in... [on a specific project] the wind sweeps through and batters the house all the time. I felt like that was a good move to insulate and re-insulate the whole house as opposed to just focusing on the new bit that you're doing. [P9]

In sum, "it's about the power of design to generate the value, which obviously you have to believe in as an architect" [P11].

Their professional expertise meant that they could see how aspects of sustainable design would lead to higher value experienced by the client and thus they sought to include such approaches and features even where the client had not requested them:

If you think there's an opportunity through passive design, to design and put a proposal together properly then you should because they're not going to ask you to do it...So sometimes I think don't often listen too hard to the client maybe, and it's time to pull away and to say 'well actually we've brought to the table design professionals, let's make a proposal'. So quite often what I have done in the past...is take the client's brief...then turn it on its head 
and offer them something else and more often than not they might be interested in the something else. [P5]

In these extracts, the architects referenced value to the client which, applying an SDL perspective, we can understand as an example from practice of the process of developing value-in-use imagined or anticipated by the architect. In some cases, they referred to an overt approach to gaining client approval for these concepts and features: "We probably push more things onto the client - have you considered this?" [P13]. In other cases, they appeared to lead the client: "The reality is, for us as architects, when you're selling it to a client whether it be a private developer client or a private homeowner is when you start saying, "It's going to help you in the long run" [P9]. In further cases, they described how they "subtly guide" the client, with insight into what will provide value:

We might say it's made out of... we're thinking it's made out of cross laminated timber but really we're talking about the fact that this will be a little suntrap and it'll have a hard floor which will take a long time to heat up, which means it'll stay nice and warm; it's a doubleheight space with an opening roof light at the top which will naturally ventilate. [P16]

Applying the SDL framework, we can understand these extracts as describing the development of the value proposition through different forms of value cocreation between provider and client. Although co-creation is inherently part of the processes of architectural design between the 'small architect' and client, the process may be subtle. The designers act as expert professionals incorporating sustainability into their designs, not necessarily in response to explicit client requirements in the brief, but as part of enhancing the potential value-in-use of their design service. This 
aligns with discussion in the literature of the need to ensure that sustainability is closely bound into the design process (Mathur, Price and Austin 2008). Sustainability is incorporated in order to provide a warm, comfortable, well-ventilated home or office, with low running costs. Value-in-use is enhanced through such benefits, and not alone, or not necessarily, through sustainability in its own right. Reference was made to how clients responded after the build in comparison to during the design process, an example of value-in-use at a point in time after delivery of the design service:

[The client] was enthusing about the fact that we'd added almost $50 \%$ to the floor area of the house but his heating bill had gone down by $40 \% \ldots$ and he was getting all excited about that, perhaps more so than he would have done during the actual design process.

Thus, in the creation of value-in-use as experienced by the client after completion of the project, the architectural designer had envisaged value beyond that which the client had been capable of imagining. By addressing sustainability as well as other aims in the design, the client's expectations were surpassed and he was 'enthused' and 'excited' about the service he received.

\section{New business}

We have described how the architectural designers here did not consider sustainable design to contribute to their marketing processes, although sustainability was incorporated into their designs as part of enhancing value-in-use to the client. How do these designers gain new business? All of our participants won most or all new business through 'word of mouth' or referral from existing, satisfied clients, supporting a relationship marketing perspective of the critical nature of the 
relationship with the client for business development. The link between value-in-use experienced by the client and referral for new work was made explicit by some participants: "I get work from word of mouth. My new model is that I will do a very nice job and other people will see it and I will get new work." [P10]. Previous studies have argued for the importance of product or service quality for customer satisfaction, retention and referral (Rust, Zahorik and Keiningham 1995, Holm 2000). Proposing an alignment between sustainability, quality and value, we argue that sustainable design does indeed play a marketing role for small designers in construction. Although often not explicitly drawn on for marketing, designers with a level of expertise in the concepts of sustainable design include sustainable thinking in their work as part of enhancing their value proposition to, and increasing the potential value-in-use to be experienced by, existing clients and thereby contributing to generation of new business through referrals.

\section{Discussion}

Despite nearly $40 \%$ of market share in the UK owned by small architectural design practices of 10 or fewer employees (The Fees Bureau, 2013), there has been very little investigation into the marketing of sustainability by small design businesses in construction. In a first study focused solely on small architectural design firms, marketing and sustainability, the current work was intended to address this gap, to gather empirical evidence of the practices of such firms, and to contribute to understanding of both marketing and sustainable construction in small businesses. Based on semi-structured interviews with 16 architectural design practices, initial analysis suggested that the small businesses saw little demand for sustainable construction and appeared to make little or no overt use of sustainable design in their 
marketing and new business development, in line with earlier studies with SMEs (Hillary 2000, Revell and Blackburn 2007). The current study sought to move beyond the preliminary findings of such earlier work and critical analysis of the responses here demonstrated a more complex situation.

\section{Understandings of sustainable design: client, architect, theory}

There were marked differences in understanding of sustainable design between the professionals and their clients, echoing the varying meanings of sustainability debated in the academic literature. Most of the designers conceptualised sustainable construction as a broad-based approach to architectural design. In contrast, clients tended to define sustainability only in terms of 'bolt-on' technologies. Clients in particular, and a small number of designers, appeared to associate sustainability with unavoidably increased costs, possibly to lack of knowledge. A small number of practices appeared to lack knowledge and personal interest in sustainability, and all of these factors may have contributed to the absence of sustainability in the designers' planned approaches to marketing. Such findings have been documented previously (Revell and Blackburn 2007) and are noted here to provide both a full account of participant responses and as premises from which to argue a more critical and nuanced account of practitioner experience. As proposed by SDL, the designers consciously and consistently sought to enhance the value of the service they offered in multiple ways beyond transactional benefits, and this included the application of the principles of sustainable design where appropriate. Such application appeared to be seen by the participants as serving the objective of enhanced value-in-use to the client at least as much as sustainability objectives per se. Congruent with earlier findings that small firms may pay little formal attention to marketing activities (Barksdale and Clopton 1984; McColl-Kennedy et al. 2008), few 
of the interviewees explicitly connected this process with business development. Nonetheless, from an analytical perspective, it represents an example from practice of the process of enhancing the value proposition beyond a cost basis, as proposed by SDL: examples were given of the potential for increased warmth and comfort as part of the client's experience of value-in-use. Thus we may suggest that sustainable design is part of an enhanced value proposition in architectural design. A novel finding was that the value proposition may not overtly reference the potential valuein-use and we discuss further below asymmetric contributions in the co-creation of value. For the designers here, new business was primarily through referral and thus the value proposition, and the value-in-use experienced by the clients, contributed to business development, even if this linkage from sustainability was not recognised by many of the designers.

In contrast to the findings of Smyth (2013) on construction majors, 'greenwash' was not in evidence for small businesses. From a marketing perspective, we suggest that small architectural designers may in fact fail to recognise the marketing potential and actual marketing role of sustainable design in their business development. Sustainability may suffer from the general tendency of small businesses to pay little formal attention to marketing, noted in the literature (Barksdale and Clopton 1994).

\section{Co-creation of value: asymmetric contributions}

In the responses of the architectural designers, there was clear evidence from practice of co-creation of value, as predicted in Vargo and Lusch's (2015) service-dominant logic, with the client contributing resources of time and expertise in their requirements to the design process. In this process, we noted asymmetric contributions. Not only did the designers contribute a much higher level of formal 
knowledge, as would be expected in a professional service offerings (Ben-Sira 1976, Sweeney et al. 2011), but also drew on their tacit knowledge of what constitutes 'good design', their knowledge of the value-in-use realised by previous clients and their insights into what was likely to be experienced as value-in-use for the current client. In this, they exemplified the argument in the literature that service providers should "focus on becoming involved in the customers' lives" (Grönroos and Voima 2013: 134). Thus the anticipation of value-in-use by the designers exceeded that of the clients, and this asymmetry may also characterise the business relationships of other professional services firms. For the private client, a construction project may be a rare, or even unique, event. For private clients and developers alike, a priori experience of value-in-use at the end of a construction project is likely to be limited and they are without an equivalent formal body of knowledge to that of professional architectural designers. Their capacity for anticipating value is inherently less than that of the designers and we argue that this will almost always be the case in the domain of sustainable design in construction.

The foregoing critical analysis leads to two major implications for the marketing of environmental sustainability. Firstly, the theoretical proposition from SDL of co-creation of value undermines arguments in previous studies that the lack of client demand prevents construction SMEs' engagement with the sustainability agenda (Hillary 2000, Revell and Blackburn 2007): co-creation implies joint responsibility. Secondly, the current finding of asymmetric co-creation in practice holds the implication that a larger share of the responsibility for proposing environmentally sustainable solutions lies with the producer, in this case, the architectural designer. This challenges arguments that 'demand pull' will lead to change towards greater environmental protection, implicit in some ecological 
modernisation perspectives (Mol and Sonnenfeld 2000). Stated simply: clients cannot demand what they do not know exists so the architectural designer carries primary responsibility for offering environmentally sustainable solutions and/or incorporating sustainability within their designs.

\section{Conceptual limitations of existing theory}

An SDL perspective enables a deeper conceptual understanding of how value is developed and realised. In particular, its proposition that value extends beyond cost challenges the predominance of cost in discourses around sustainability in construction. However, its application to sustainable construction points to an area for further development. Value-in-use is defined in respect of the phenomenology of the beneficiary (Vargo and Lusch 2008). A recent framework for assessment considered both individual and organisational experience of value-in-use (Macdonald et al. 2011) and Vargo and Lusch (2015) recently extended their conceptualisation of SDL to acknowledge multiple actors and multiple beneficiaries of an exchange. When it comes to the objectives of sustainable construction, the potential beneficiaries include not only the individual or organisational client (through use of the building), but also the local community (through avoidance of additional traffic, for example), national society (through minimising impact on water courses, for example), international society and future generations (through minimising energy consumption and $\mathrm{CO}_{2}$ emissions). These are important beneficiaries for consideration in construction. While these are captured at a conceptual level in the most recent developments of SDL, there remains a crucial omission: the natural environment. Despite the extension of SDL to encompass cultural or service 'ecosystems' as contexts in which service exchanges are embedded, the natural world - source of all material resources for exchange - is overlooked. The adoption 
of the term 'ecosystem' by Vargo and Lusch (2015) is unfortunate as it re-defines common or lay understanding to consider only human cultural arrangements, excluding other biological and non-biological systems.

This points to a related topic for future theoretical extension. The 'positive statement' on the co-creation of value in human exchange networks (Vargo \& Lusch 2015) has a negative equivalent yet to be conceptually theorised: for any exchange, there may be dis-beneficiaries. An exchange may deliver value for some actors but dis-benefits for others. This is an important topic for marketing theory due to the potentially negative impact on brand and on business development of poor corporate social or environmental responsibility. We encourage marketing researchers to seek to expand understanding of value-in-use so that benefits and dis-benefits to natural ecological systems, wider society and future generations are incorporated. Sustainability from environmental, as well as social and economic, perspectives is increasing recognised as critical to strategic marketing of large organisations. Enhanced conceptual tools are needed to keep pace.

Despite the 'hope' that BREEAM and similar assessment schemes will drive market demand, the findings here suggest that, as yet, it does not feature strongly in the views of architectural designers in small practices, nor is it perceived to provide a marketing benefit. These findings are in line with studies that have attempted to quantify market benefits of BREEAM, which show little evidence of effect thus far (Fuerst and Mcallister 2011). BREEAM may have differing potential as a marketing tool for different size of practice, and the findings here suggest it has low relevance for small practices, despite the introduction of BREEAM for Domestic Refurbishment in 2012. 


\section{Research limitations}

Limitations of the current study should be acknowledged. While we cannot make claims as to how widespread such experiences may be, we can propose that the experiences and views expressed by our participants exist within the industry in the UK, and in particular on small projects. As the research was combined with an offer of basic eco-training, it is likely that the participant firms excluded practices with strong credentials in environmental sustainability. Further, it is likely that most of the participants had some personal interest in environmental sustainability and may not be statistically representative of architectural designers more generally. However, the perception of a limited role for sustainability in marketing, with participants who may have been biased in favour of sustainable design, suggests that the challenges perceived by the participants may in fact be more prevalent in the industry at large. The firms interviewed were based in and around London and may not represent the industry nationally. Future research could usefully explore other small businesses in construction, such as structural and mechanical and electrical engineers. With initial findings here from micro firms, a future study could usefully explore the differences between small and large businesses in construction.

\section{Conclusions}

Applying a critical realist approach to analysis has enabled the findings here to move beyond previous work. Where earlier studies noted the absence of client demand as a barrier to engagement in sustainable marketing, harnessing insights from SDL on cocreation of value, we argue that co-creation entails joint responsibility. The current study has pointed to the difficulties for both scholars and practitioners in gaining consensus on the meaning of sustainability, leading to the question 'client demand for what?' In finding a deep asymmetry between architect and client understandings 
of sustainability, and arguing that such asymmetry is inherent in the roles of expert/professional and client, the conclusion is that market demand will continue to fall short of professional knowledge. The onus thus rests on architectural designers to a greater extent to inform, advise and offer greater levels of sustainability in construction design, and therefore in marketing their services.

Where earlier studies noted cost as a barrier, the current study has pointed to values beyond cost which are discussed and negotiated between architect and client. Drawing on theoretical insights from SDL which has mapped a shift in emphasis from price to value in service exchange, discussions on the many facets of value can be seen as part of the day-to-day co-creation of value in design. The conclusion is that sustainability in design is an important aspect of value creation, that this was understood implicitly by architectural designers in the current study but was not realised in their marketing. Sustainability therefore offers the potential to contribute more strongly to marketing than is now the case for small practices. Further, marketing theory has yet to represent adequately a broader conceptualisation of value-in-use, to consider value in a construction project from the perspective of natural ecological systems, wider society and future generations, and to consider the potential for dis-benefits from exchange.

In summary, the application of a critical realist approach, and the theoretical framework of SDL, has moved understanding of marketing sustainability in small businesses beyond the discourses of customer demand, knowledge and cost. Perhaps due to these constraining discourses, small firms have appeared to remain disengaged from sustainability and marketing. However, the findings suggest that sustainability is playing a more important role in business development for small architectural designers than is realised and the conclusions argue for the crucial role of the 
architectural designer in guiding clients towards greater environmental sustainability and in negotiating value in the widest sense. 


\section{References}

Ambec, S and Lanoie, P (2008) Does it pay to be green? A systematic overview. Academy of Management Perspectives, 22(4), 45-62.

Ates, A and Bititci, U (2011) Change process: A key enabler for building resilient smes. International Journal of Production Research, 49(18), 5601-18.

Barksdale, H C and Clopton, S W (1994) Patterns of marketing activity among architectural design firms. Journal of professional services marketing, 11(1), 101-26.

Ben-Sira, Z (1976) The function of the professional's affective behavior in client satisfaction: A revised approach to social interaction theory. Journal of Health and Social Behavior, 17, 3-11.

Blau, J R (1984) Architects and firms. Boston: MIT Press.

Braun, V and Clarke, V (2006) Using thematic analysis in psychology. Qualitative Research in Psychology, 3(2), 77-101.

Chan, H K, He, H and Wang, W Y C (2012) Green marketing and its impact on supply chain management in industrial markets. Industrial Marketing Management, 41(4), 557-62.

Chen, Y-S and Chang, C-H (2013) Greenwash and green trust: The mediation effects of green consumer confusion and green perceived risk. Journal of Business Ethics, 114(3), 489-500.

Christie, L, Donn, M and Walton, D (2011) The 'apparent disconnect' towards the adoption of energy-efficient technologies. Building Research and Information, 39(5), 450-8.

Cole, R J (2011) Motivating stakeholders to deliver environmental change. Building Research and Information, 39(5), 431-5.

Coviello, N E, Brodie, R J and Munro, H J (2000) An investigation of marketing practice by firm size. Journal of Business Venturing, 15, 523-45.

Czinkota, M, Kaufmann, H R and Basile, G (2014) The relationship between legitimacy, reputation, sustainabilty and branding for companies and their supply chains. Industrial Marketing Management, 43(1), 91-101.

Devall, B (1991) Deep ecology and radical environmentalism. Society and Natural Resources: An Internationl Journal, 4(3), 247-58.

Dodds, R, Graci, S, Ko, S and Walker, L (2013) What drives environmental sustainability in the new zealand wine industry? An examination of driving factors and practices. International Journal of Wine Business Research, 25(3), 161-84.

Elkington, J (1997) Cannibals with forks: The triple nottom line of twenty 21 st century business. Oxford: Capstone.

EU (2015) Construction and demolition waste (CDW). http://bit.ly/1ERulE1. Accessed 18.9.2015.

Farmer, G and Guy, S (2010) Making morality: Sustainable architecture and the pragmatic imagination. Building Research and Information, 38(4), 368-78.

Finne, A and Gronroos, C (2006) Towards a dynamic communication model: A useful tool in relationship communication, Swedish School of Economics and Business Administration.

Fuerst, F and McAllister, P (2011) The impact of energy performance certificates on the rental and capital values of commercial property assets. Energy Policy, 39(10), 6608-14. 
Grönroos, C (1996) Relationship marketing: Strategic and tactical implications. Management Decision, 34(3), 5-14.

Grönroos, C and Voima, P (2013) Critical service logic: Making sense of value creation and co-creation. Journal of the Academy of Marketing Science, 41, 133-50.

Gummesson, E (1978) Toward a theory of professional service marketing. Industrial Marketing Management, 7(2), 89-95.

Halliday, S (2007) Sustainable construction. London: Routledge.

Harré, R (2009) Saving critical realism. Journal for the Theory of Social Behaviour, 39(2), 129-43.

Hill, R C and Bowen, P (1997) Sustainable construction: Principles and a framework for attainment. Construction Management and Economics, 15(3), 223-39.

Hillary, R (2000) Small and medium-sized enterprises and the environment. Sheffield: Greenleaf Publishing.

HMG (2008) Strategy for sustainable construction. http://bit.ly/1WX69ti. Accessed on 12.10.2015.

Holm, M G (2000) Service quality and product quality in housing refurbishment. International journal of quality and reliability management, 17(4/5), 527-40.

Hopwood, B, Mellor, M and O'Brien, G (2005) Sustainable development: Mapping different approaches. Sustainable Development, 13, 38-52.

Johnston, P, Everard, M, Santillo, D and Robert, K-H (2007) Reclaiming the definition of sustainability. Enviromental Science Pollution Research, 14(1), 60-6.

Kibert, C J (2007) The next generation of sustainable construction. Building Research and Information, 35(6), 595-601.

Kibert, C J, Sendzimir, J and Guy, B (2000) Construction ecology and metabolism: Natural system analogues for a sustainable built environment Construction Management and Economics, 18(8), 903-16.

Knight, Z, Chan, W-S and Singh, C (2014) Sizing energy efficiency investment, http://bit.ly/1vNT4UU. Accessed 18.9.2015.

Lee, W L (2013) A comprehensive review of metrics of building environmental assessment schemes. Energy and Buildings, 62, 403-13.

Leonidou, C, Katsikeas, C and Morgan, N (2013) 'Greening' the marketing mix: Do firms do it and does it pay off? Journal of the Academy of Marketing Science, 41(2), 151-70.

Li, H and Cai, W (2008) Green marketing and sustainable development of garment industry: A game between cost and profit. International Journal of Business and Management, 3(12), 81-5.

Liu, S, Kasturiratne, D and Moizer, J (2012) A hub-and-spoke model for multidimensional integration of green marketing and sustainable supply chain management. Industrial Marketing Management, 41(4), 581-8.

Lyon, T P and Montgomery, A W (2013) Tweetjacked: The impact of social media on corporate greenwash. Journal of Business Ethics, 118(4), 747-57.

Macdonald, E K, Wilson, H, Martinez, V and Toossi, A (2011) Assessing value-inuse: A conceptual framework and exploratory study. Industrial Marketing Management, 40(5), 671-82.

Mathur, V N, Price, A and Austin, S (2008) Conceptualizing stakeholder engagement in the context of sustainability and its assessment. Construction Management and Economics, 26(6), 601-9. 
Mayer, R C, Davis, J H and Schoorman, F D (1995) An integrative model of organizational trust. Academy of Management Review, 20(3), 709-34.

McColl-Kennedy, J R, Sweeney, J C, Soutar, G N and Amonini, C (2008) Professional service firms are relationship marketers: But does size matter? Australasian Marketing Journal, 16(1), 30-47.

Menon, A and Menon, A (1997) Enviropreneurial marketing strategy: The emergence of corporate environmentalism as a marketing strategy. Journal of Marketing, 61(1), 51-67.

Miller, D and Merrilees, B (2013) Linking retailer corporate brand and environmental sustainability practices. Journal of Product and Brand Management, 22(7), 437-43.

Mol, A P J and Sonnenfeld, D A (2000) Ecological modernisation around the world: Perspectives and critical debates. London: Frank Cass Publishers.

Myers, D (2005) A review of construction companies' attitudes to sustainability. Construction Management and Economics, 23(8), 781-5.

Palmatier, R W, Burke Jarvis, C, Bechkoff, J R and Kardes, F R (2009) The role of customer gratitude in relationship marketing. Journal of Marketing, 73(Sept), $1-18$.

Payne, A and Frow, P (2005) A strategic framework for customer relationship management. Journal of Marketing, 69(4), 167-76.

Polonsky, M J and Rosenberg, P J I (2001) Re-evaluating green marketing: A strategic approach. Business Horizons, 44(Sept-Oct).

Raju, P S, Lonial, S C and Crum, M D (2011) Market orientation in the context of smes: A conceptual framework. Journal of Business Research, 64(12), 13206.

Reid, M (2008) Contemporary marketing in professional services. Journal of Services Marketing, 22(5), 374-84.

Revell, A and Blackburn, R (2007) The business case for sustainability? An examination of small firms in the UK's construction and restaurant. Business Strategy and the Environment, 16(6), 404-20.

Rittel, H W J and Webber, M M (1973) Dilemmas in a general theory of planning. Policy Sciences, 4, 155-69.

Rust, R T, Zahorik, A J and Keiningham, T I (1995) Return on quality: Making service quality financially accountable. Journal of Marketing, 59(April), 5870.

Sarkis, J, Gonzalez-Torre, P and Adenso-Diaz, B (2010) Stakeholder pressure and the adoption of environmental practices: The mediating effect of training. Journal of Operations Management, 28(2), 163-76.

Schneiderová Heralová, R (2011) Sustainable buildings: Market value and market share. Organization, Technology \& Management in Construction: An International Journal, 3(1), 250-3.

Schweber, L (2013) The effect of breeam on clients and construction professionals. Building Research and Information, 41(2), 129-45.

Smyth, H (2013) Green or maturing? Environmental sustainability in marketing and business development amongst construction majors. In: 7th Nordic Conference on Construction Economics and Organization, Klakegg, O J, Ed., Trondheim: Akademika Forlag, 1-13.

Smyth, H (2015) Relationship management and the management of projects. Abingdon, Oxfordshire: Routledge 
Smyth, H and Morris, P W G (2007) An epistemological evaluation of research into projects and their management: Methodological issues. International Journal of Project Management, 25, 423-36.

Smyth, H and Fitch, T (2009) Application of relationship marketing and management: A large contractor case study. Construction Management and Economics, 27(4), 399-410.

Smyth, H and Kioussi, S (2011) Architecture firms and the role of brand management. Architectural Engineering and Design Management, 7(3), 20517.

Sullivan, C C (2000) Differentiating design services. Building design and construction, 41(6), 44-8.

Sweeney, J C, Soutar, G N and McColl-Kennedy, J R (2011) The marketing practices-performance relationship in professional service firms. Journal of Service Management, 3, 292-316.

Szokolay, S V (2014) Introduction to architectural science: The basis of sustainable design. 3rd ed. Abingdon, Oxfordshire: Routledge.

The Climate Group (2015) Re100. http://bit.ly/1pdBGVw. Accessed 18.9.2015.

The Fees Bureau (2013) Architects' performance 2014 edition, West Sussex: The Fees Bureau/Mirza \& Nacey Research Ltd.

United Nations Environment Programme (2014) Greening the building supply chain. http://bit.ly/1Om7hBn. Accessed 18.9.2015.

Vargo, S L and Lusch, R F (2004) Evolving to a new dominant logic for marketing. Journal of Marketing, 68(1), 1-17.

Vargo, S L and Lusch, R F (2008) Service-dominant logic: Continuing the evolution. Journal of the Academy of Marketing Science, 36, 1-10.

Vargo, S L and Lusch, R F (2015) Institutions and axioms: An extension and update of service-dominant logic. Journal of the Academy of Marketing Science. Online. doi: 10.1007/s11747-015-0456-3.

Winch, G M and Schneider, E (1993) Managing the knowledge-based organization: The case of architectural practice. Journal of Management Studies, 30, 92337.

World Commission on Environment and Development (1987) Our common future, Oxford: WCED.

i The term 'small practices' is used, following Royal Institute of British Architects usage, to indicate firms with 10 or fewer employees. The European Union defines such businesses as micro, with small firms as under 50 and medium firms from 50 to 249 employees, collectively termed SMEs.

ii Sustainability generically refers to 'the triple bottom line' of environment, society and economics (Elkington 1997). Due to practical constraints, the current study focused on environment. 